\title{
Determining the Porosity and Saturated Hydraulic Conductivity of Binary Mixtures
}

\section{ZF Zhang \\ AL Ward \\ JM Keller}

September 2009

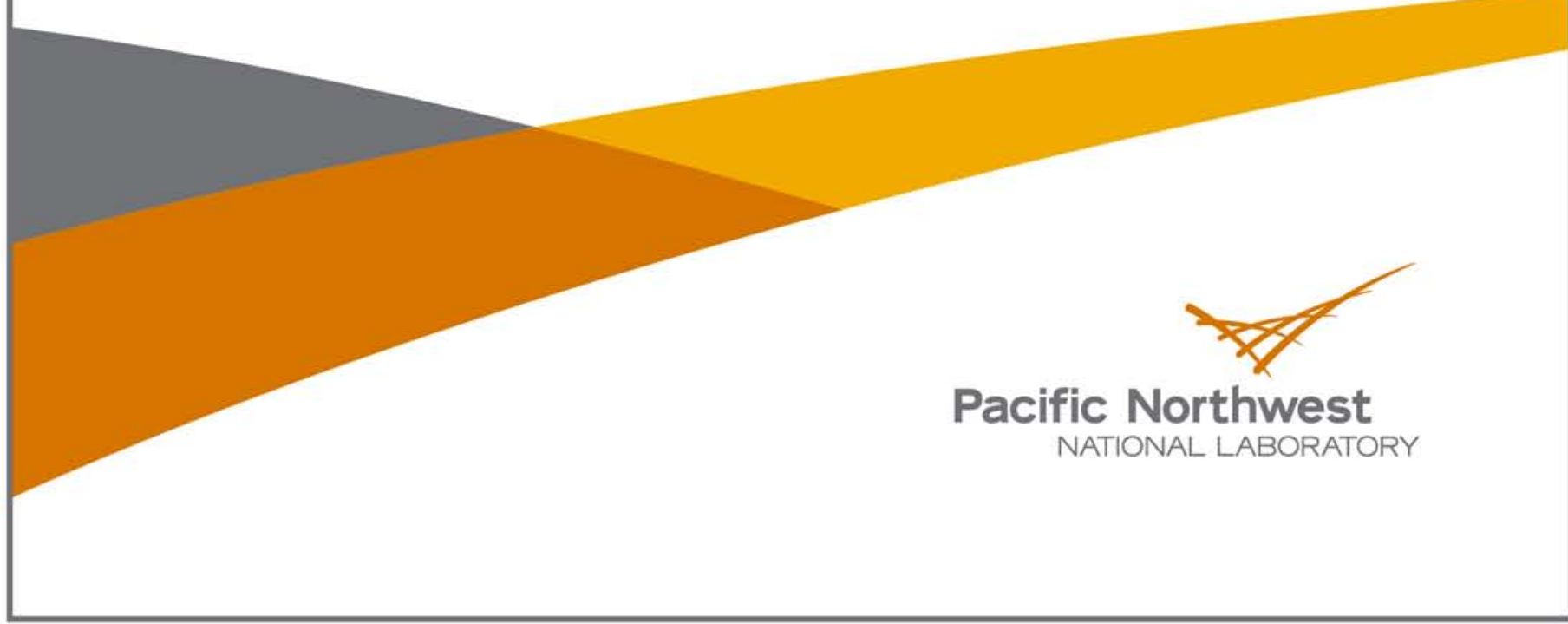




\title{
DISCLAIMER
}

This report was prepared as an account of work sponsored by an agency of the United States Government. Neither the United States Government nor any agency thereof, nor Battelle Memorial Institute, nor any of their employees, makes any warranty, express or implied, or assumes any legal liability or responsibility for the accuracy, completeness, or usefulness of any information, apparatus, product, or process disclosed, or represents that its use would not infringe privately owned rights. Reference herein to any specific commercial product, process, or service by trade name, trademark, manufacturer, or otherwise does not necessarily constitute or imply its endorsement, recommendation, or favoring by the United States Government or any agency thereof, or Battelle Memorial Institute. The views and opinions of authors expressed herein do not necessarily state or reflect those of the United States Government or any agency thereof.

\author{
PACIFIC NORTHWEST NATIONAL LABORATORY \\ operated by \\ BATTELLE \\ for the \\ UNITED STATES DEPARTMENT OF ENERGY \\ under Contract DE-AC05-76RL01830
}

Printed in the United States of America

Available to DOE and DOE contractors from the

Office of Scientific and Technical Information,

P.O. Box 62, Oak Ridge, TN 37831-0062;

ph: (865) 576-8401

fax: (865) 576-5728

email: reports@adonis.osti.gov

\author{
Available to the public from the National Technical Information Service, \\ U.S. Department of Commerce, 5285 Port Royal Rd., Springfield, VA 22161 \\ ph: (800) 553-6847 \\ fax: (703) 605-6900 \\ email: orders@ntis.fedworld.gov \\ online ordering: http://www.ntis.gov/ordering.htm
}

This document was printed on recycled paper. 


\title{
Determining the Porosity and Saturated Hydraulic Conductivity of Binary Mixtures
}

\author{
ZF Zhang ${ }^{1}$ \\ AL Ward ${ }^{1}$ \\ JM Keller ${ }^{2}$
}

September 2009

Prepared for

the U.S. Department of Energy

under Contract DE-AC05-76RL01830

Pacific Northwest National Laboratory

Richland, Washington 99352

\footnotetext{
${ }^{1}$ Pacific Northwest National Laboratory

${ }^{2}$ GeoSystems Analysis, Inc.
} 



\begin{abstract}
Gravels and coarse sands make up significant portions of some environmentally important sediments, while the hydraulic properties of the sediments are typically obtained in the laboratory using only the fine fraction (e.g., $<2 \mathrm{~mm}$ or $4.75 \mathrm{~mm}$ ). Researchers have found that the content of gravel has significant impacts on the hydraulic properties of the bulk soils. Under the study reported here, Laboratory experiments were conducted to measure the porosity and the saturated hydraulic conductivity of binary mixtures with different fractions of coarse and fine components. We proposed a mixing-coefficient model to estimate the porosity and a power-averaging method to determine the effective particle diameter and further to predict the saturated hydraulic conductivity of binary mixtures. The proposed methods were able to estimate the porosity and saturated hydraulic conductivity of the binary mixtures for the full range of gravel contents and were successfully applied to two datasets in the literature.
\end{abstract}





\section{Acknowledgments}

The laboratory experiments and preliminary data analyses were carried out and part of this report was drafted in fiscal years 2005 and 2006 with funding provided by the U.S. Department of Energy's Remediation and Closure Science Project managed by Mark D. Freshley. The work was presented in the Soil Science Society of America’s 2005 Annual Meeting in Salt Lake City, Utah. Christopher E. Strickland assisted in designing the system for measuring the saturated hydraulic conductivity. Additional funding was provided by the CH2M HILL Plateau Remediation Company's Remediation Decision Support project managed by George V. Last in fiscal year 2009 for further data analysis and completion of this report. 



\section{Contents}

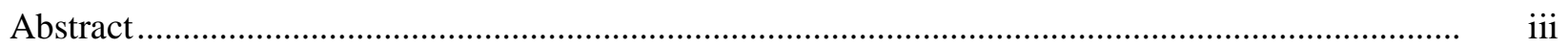

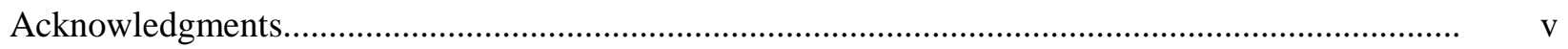

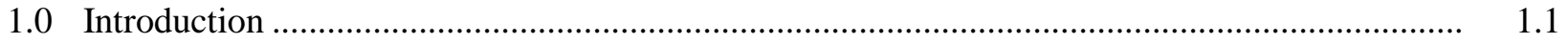

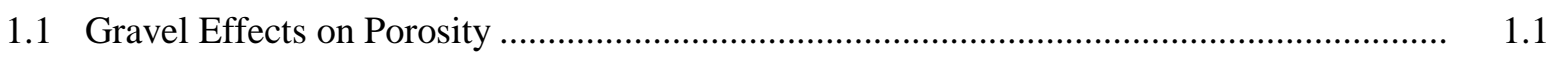

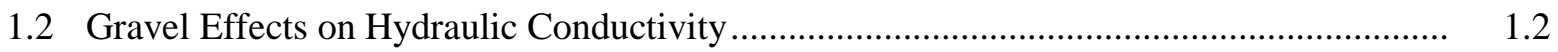

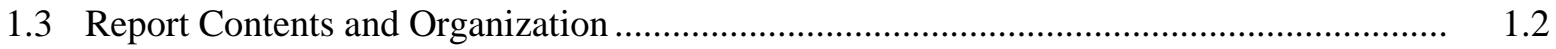

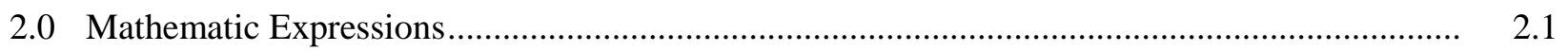

2.1 Estimating the Porosity of a Binary Mixture................................................................. 2.1

2.2 Estimating Hydraulic Conductivity of a Mixture .............................................................. 2.2

3.0 Materials and Methods ................................................................................................. 3.1

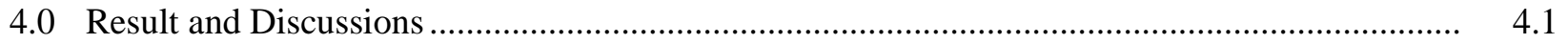

4.1 Porosity and the Mixing Coefficient .............................................................................. 4.1

4.2 Saturated Hydraulic Conductivity of Mixtures ............................................................. 4.1

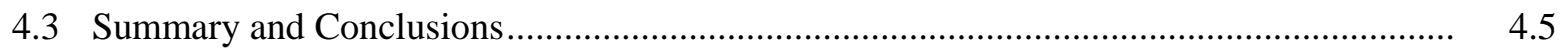

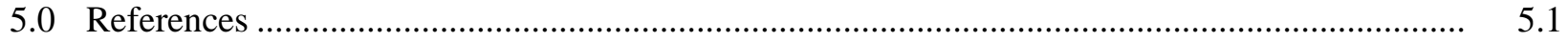




\section{Figures}

2.1 Diagram Showing the Porosity Variation with the Fraction of the Coarse Component of

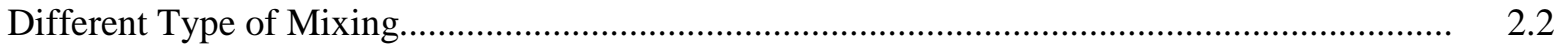

2.2 Typical Curves of Power $p$ versus the Coarse Fraction Described by Eq. (2.7) .......................... 2.4

4.1 Measured and Predicted Porosities of Mixtures of Coarse and Fine Components ....................... 4.2

4.2 Mixing Coefficients of Mixtures of Coarse and Fine Components .......................................... 4.3

4.3 The Average Mixing Coefficients of Mixtures of Coarse and Fine Components ....................... 4.3

4.4 Measured and Predicted Saturated Hydraulic Conductivities of Binary Mixtures when Zero-Mixing, Ideal-Mixing, and Mixing-Coefficient Porosity Models were Used...................... $\quad 4.4$

4.5 Comparison of Predicted Saturated Hydraulic Conductivity and Measured Data from Marion (1990) and Shakoor and Cook (1990) ......................................................................... 4.6

\section{Tables}

3.1 Mixtures of Coarse and Fine Components Used ..................................................................

3.2 Properties of the Pure Phase Components ......................................................................... 


\subsection{Introduction}

Gravels make up significant portions of some environmentally important sediments but often are paid less attention than the finer components. For example, the Hanford vadose zone underlying radioactive waste tanks in south-central Washington State contains substantial regions characterized as gravelly sands and sandy gravels. Some of the soils contain more than $60 \%$ gravels (particle diameter $>2 \mathrm{~mm}$ ) (Khaleel and Freeman 1995). Effective closure of mine wastes, which contain large amounts of gravels, requires predicting the heap leach draindown and long-term groundwater impacts from waste facilities (Milczarek et al. 2006). Gravels are also an important component in engineered capillary barriers (Ross 1990; Selker 1997; Conca et al. 1998) or compacted soil liners (Shelly and Daniel 1993) for subsurface waste isolation.

Gravels are typically defined as the particles that are retained on No. 4 (4.75-mm) sieve (ASTM 2002) or the particles larger than 2 mm (Soil Survey Staff 1975; Gee and Or 2002). Because agricultural soils often have relatively low gravel contents, gravelly soils are studied less frequently than soils with negligible amounts of gravels. Furthermore, most laboratory measurements of the hydraulic properties of soils are limited to the fine earth fraction ( $<2-$ or $<4.75$-mm fraction). Determining properties for soils containing rock fragments requires either in situ measurements, sometimes impractically large measurement apparatuses (e.g., soil column), or procedures that adjust fine earth material properties for the coarse fraction content. Nevertheless, the presence of gravels modifies the porosity and pore connectivity/ tortuosity and hence affects the hydraulic conductivity. Researchers have found that, depending on the relative proportion of the coarse and fine components, the inclusion of gravels in the finer component may increase or decrease the porosity and hydraulic conductivity of a mixture. For natural soils, the two components of a mixture are a $<2$ - (or 4.75-) mm matrix (i.e., fines) and $\geq 2$ - (or 4.75-) $\mathrm{mm}$ gravels (i.e., coarse component). A mixture may also be divided into multiple components and then more comprehensive methods are needed to estimate the hydraulic properties of the mixture.

This report briefly describes the results of a study in support of the U.S. Department of Energy's Remediation and Closure Science Project and the CH2M HILL Plateau Remediation Company's Remediation Decision Support project. It reviews the experimental findings and models used to predict the impacts of gravel on the porosity and the saturated hydraulic conductivity of binary mixtures. The gravel impacts on soil water retention and unsaturated hydraulic conductivity were not considered.

\subsection{Gravel Effects on Porosity}

Laboratory and theoretical studies have found that, 1) the porosity of a binary mixture, $\phi_{m}$, depends on the fraction of each particle size population and the ratio of the particle diameters; 2) the porosity of a mixture of large and small particles is less than the linear combination of the porosities of the pure components; and 3) a porosity minimum is often observed for binary mixtures. This minimum theoretically occurs when small particles completely fill the voids of the load-bearing larger particles. Porosity values decrease when the sediment mixture is compacted; however, the porosity minimum and observed features still occur.

Clark (1979) identified two types of particle packing, “coarse packing” and "fine packing,” in binary mixtures. In coarse packing, smaller particles are contained in the pore space created by load-bearing coarse-grained particles, while, in fine packing, larger particles disperse in a fine-grained matrix. Development of quantitative porosity relationships has been based on the assumption of "ideal packing," 
that is, only one type of particle packing (coarse or fine) occurs at a time and each particle type does not disturb the packing of the other particle type. Comparisons of data to predictions made with the ideal packing model show consistent under-predictions of porosity for sediment mixtures. Predicted porosities for angular coarse particles deviate even further from the ideal packing model (Shakoor and Cook 1990).

Peck and Watson (1979) used heat flow analogy to obtain expressions for the bulk hydraulic conductivity of a medium with spherical inclusions of different hydraulic conductivity. Bouwer and Rice (1984) assumed that the ratio of $K_{s}$ of the mixture to that of the fine fraction is equal to the void ratio of the mixture to that of the sand. Both of these models are only applicable to the mixtures that the fine fraction dominates (ideal fine packing). When the volume fraction of fine grains is less than the porosity of the coarse-grained fragment, some fine grains are distributed in the pore space of the coarse-grained component, while the remaining fine grains displace the coarse grains. Koltermann and Gorelick (1995) modified the ideal packing model by introducing a weighting coefficient, $y$, that reflects the relative proportions of coarse and fine packing and varies between one and a minimum value. Their results showed that the modified model, which they called the fractional-packing model, predicted the porosities of mixtures better than the ideal model. However, the physical meaning of the $y$ coefficient in the fractional packing is not very clear. Furthermore, we found that, when $y_{\min }$ is very small, the minimum porosity does not occur at $y_{\min }$ as it should. Kamann et al. (2007) also found this problem and hence extended the model as the piecewise-linear fractional-packing model for porosity calculation.

\subsection{Gravel Effects on Hydraulic Conductivity}

Under the study reported here, we focused on research in which gravels were mixed with a matrix as opposed to cases where gravels were placed on a soil surface as a covering layer. Mehuys et al. (1975) experimented with stony desert soils (up to $40 \%$ by mass of gravels with particle diameter $>2 \mathrm{~mm}$ ) and found that the presence of stones had no appreciable effect on the relationship between unsaturated hydraulic conductivity, $K$, and pressure head of soil water, $\psi$. Infiltration in stony soils decreases with increasing rock content because of the less accessible surface for water flow (Valentin 1994).

Furthermore, the more spherical rock fragments are, the lower the saturated hydraulic conductivity (Dunn and Mehuys 1984). Marion (1990) and Shakoor and Cook (1990) measured the permeability of a sand/clay and a gravel/silty clay mixture, respectively. They found that the effects of the fraction of finegrained materials on the measured permeabilities of the mixtures were more complex. At either the very low or very high fraction of fine-grained material, the permeability of the mixture did not vary significantly. However, the permeability of the mixture varied by several orders of magnitude with a small change of fines content at some critical value. Milczerek et al. (2006) and Kamann (2007) observed similar results.

\subsection{Report Contents and Organization}

In this report, we introduce a mixing-coefficient model to estimate the porosity and a poweraveraging method to estimate the representative particle diameter of a binary mixture. The saturated hydraulic conductivity of the mixture is then predicted using the Kozeny-Carman equation (Bear 1972) based on the representative grain diameter of the mixture. The proposed methods were tested with laboratory experiments that measured the porosity and saturated hydraulic conductivity of different mixtures of coarse and fine components and with data from the literature. The ensuing sections describe 
the associated mathematical expressions, materials and methods used, and study results and related discussion, summary, and conclusions. 



\subsection{Mathematic Expressions}

The mathematical expressions for estimating the porosity of a binary mixture and the hydraulic conductivity of a mixture are described in the following sections.

\subsection{Estimating the Porosity of a Binary Mixture}

Under our mixing-coefficient model, we first introduce the porosity upper and lower bounds of a mixture based on the existing theory. Then the mixing-coefficient model is introduced to estimate the porosity of a mixture with a certain degree of mixing.

The upper bound of porosity of a binary mixture is determined by assuming that the two components are packed without mixing with one another. Hence, the upper bound of $\phi_{m}$ of a binary mixture is simply the linear interpolation of the porosity of the coarse component, $\phi_{c}$, and that of the fine component, $\phi_{f}$ :

$$
\phi_{m}^{u b}=b_{v c} \phi_{c}+b_{v f} \phi_{f}
$$

where superscripts ' $u b$ ' denote for the "upper bound," subscripts ' $c$ ' the coarse component, and ' $f$ ' the fine component, and $b_{v}$ is the volume fraction of a component and $b_{v c}+b_{v f}=1$. This is referred to as the zero-mixing model.

The lower bound of $\phi_{m}$ is determined by assuming that the two components are fully mixed. When the volume fraction of fines is less than the porosity of the coarse-grained component, $\phi_{c}$, all fines are contained within the voids created by the coarse grains. When the volume fraction of fines is greater than $\phi_{c}$, coarse grains are dispersed throughout a matrix of fine grains and the porosity of the mixture solely a function of the volume fraction of fine grains. Hence, the lower bound of $\phi_{m}$ of a binary mixture based on the ideal packing model is (Clark 1979):

$$
\phi^{l b}=\left\{\begin{array}{c}
\phi_{c}-b_{v f}\left(1-\phi_{f}\right) \quad \text { if } \quad b_{v f}<\phi_{c} \\
b_{v f} \phi_{f} \text { if } \quad b_{v f} \geq \phi_{c}
\end{array}\right.
$$

where superscript 'lb’ denotes for the 'lower bound.'

In reality, two components are often not fully mixed and the porosity of a mixture lies between the upper and the lower bounds. For example, Yu et al. (1997) found that poured packing produced larger porosity and hence less mixing between the coarse and fine components than tapped packing. In the field, the mixing coefficient for a specific mixture is dependent on the formation history of the material.

Generally, the ideal packing model underestimates the porosity of a mixture because one almost can never achieve ideal packing. Predicted porosities for angular coarse particles deviate even further from the ideal 
packing model (Shakoor and Cook 1990). Here we introduce a mixing coefficient, $\lambda$, which varies between 0 and 1 to quantify the degree of mixing as follows:

$$
\lambda=\frac{\phi^{u b}-\phi_{m}}{\phi^{u b}-\phi^{l b}}
$$

Equation (2.3) shows that, when $\phi_{m}=\phi^{u b}, \lambda=0$ indicating zero mixing; and, when $\phi_{m}=\phi^{l b}, \lambda=1$ indicating ideal packing. Hence, the porosity of a mixture varies between $\phi^{l b}$ and $\phi^{u b}$ (Figure 2.1). The actual value of $\lambda$ is dependent on the mixing condition and the properties of the two components. A poor mixing procedure (e.g., poured packing) will produce a lower $\lambda$ value and a good mixing procedure (e.g., tapped packing) will lead to a higher $\lambda$ value. Substituting Equations (2.1) and (2.2) into Equation (2.3) and rearranging yields the relationship for calculating the porosity of a mixture to be

$$
\phi_{m}=\left\{\begin{array}{c}
\left(b_{v c}-\lambda b_{v c}+\lambda\right) \phi_{c}+b_{v f} \phi_{f}-\lambda b_{v c} \quad \text { if } \quad b_{v f}<\phi_{c} \\
(1-\lambda) b_{v c} \phi_{c}+b_{v f} \phi_{f} \quad \text { if } \quad b_{v f} \geq \phi_{c}
\end{array}\right.
$$

Equation (2.4) reduces to Equation (2.1) if $\lambda=0$ and to Equation (2.2) if $\lambda=1$ and will be referred to as the mixing-coefficient model. Because the zero-mixing and the ideal-packing models produce the same results when $b_{v f}=0$ or $1, \lambda$ has the largest impact on $\phi_{m}$ at $b_{v f}=\phi_{c}$ and a smaller impact when $b_{v f}$ deviates from $\phi_{c}$ (Figure 2.1). Once the mixing coefficient is known, the porosity of the mixture can be determined with Equation (2.4).

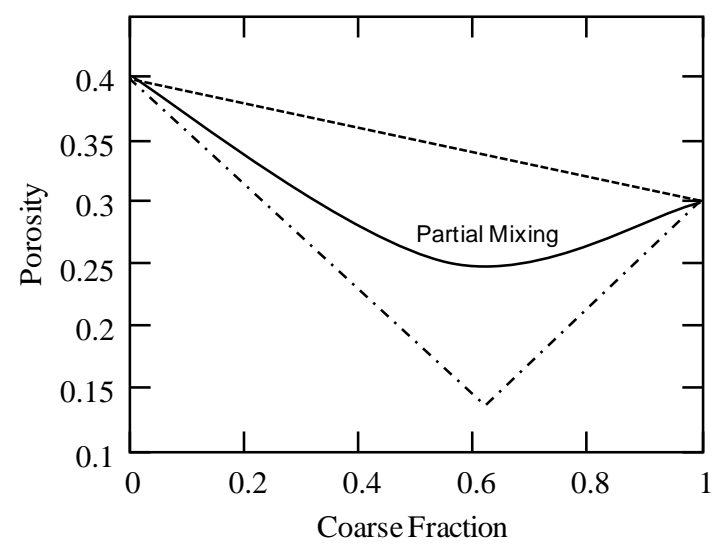

Figure 2.1. Diagram Showing the Porosity Variation with the Fraction of the Coarse Component of Different Type of Mixing

\subsection{Estimating Hydraulic Conductivity of a Mixture}

Quantitative relationships for hydraulic conductivity versus mean grain size have been developed by analogy to pipe flow and flow in capillaries (e.g., Kozeny 1927; Carman 1937). The Kozeny (1927) and Carman (1937) equations have been modified by a few researchers (e.g., Collins 1961; Bear 1972; de Marsily 1986). These equations include the effects of both particle diameter and porosity on hydraulic conductivity. Koltermann and Gorelick (1995) compared five different equations and found that the 
original Kozeny-Carman equation (Carman 1937; Bear 1972) lies approximately in the center of the possible relations. They used the Kozeny-Carman equation to estimate the hydraulic conductivity of binary mixtures as follows:

$$
K_{s m}=\left(\frac{\rho g}{\mu}\right)\left[\frac{d_{m}^{2} \phi_{m}^{3}}{180(1-\phi)^{2}}\right]
$$

where $\quad K_{s m}=$ the saturated hydraulic conductivity of a mixture

$d_{m}=$ the representative particle diameter of the mixture

$\rho=$ fluid density

$g=$ gravitational acceleration

$\mu=$ dynamic viscosity.

A difficulty in applying the Kozeny-Carman equation to estimate $K_{s m}$ is how to determine the representative particle diameter. Bear (1972) recommends using the harmonic mean particle diameter for a porous medium. Koltermann and Gorelick (1995) used the geometric and harmonic means to calculate representative particle diameters for the high and low fraction of the coarse component, respectively. However, this approach produces a discontinuity when the fraction of the coarse component is at the intermediate level. In other words, the average method is undefined for mixtures with neither of the components being dominant. The same method was used by Kamann et al. (2007). To overcome the problem of discontinuity, a power-averaging method is introduced to determine the representative particle-diameter of a binary mixture, $d_{m}$ :

$$
d_{m}=\left(b_{v c} d_{c}^{p}+b_{v f} d_{f}^{p}\right)^{1 / p}
$$

where $d_{c}$ and $d_{f}$ are the mean particle diameters of the coarse and fine components, respectively, and $p$ is a coefficient that varies sigmoidally from -1 to 0 as the $b_{v c}$ increases from 0 to 1 . The coefficient $p$ may be estimated empirically by

$$
p=\frac{1}{1+\exp \left[a\left(b_{v c 0}-b_{v c}\right)\right]}-1
$$

where $b_{v c 0}$ is the critical fraction of the coarse component, near which $K_{s m}$ varies significantly with $b_{v c}$, and $a$ is a shape factor that controls the steepness of the $p$ vs. $b_{v c}$ curve near $b_{v c}=b_{v c 0}$ (Figure 2.2). A good approximation for $b_{v c 0}$ is $b_{v c 0}=1-\phi_{c}$, at which the porosity reaches its minimum. We found by trial and error that letting $a=20$ seemed acceptable for all of the mixtures investigated in our work and those investigated by Marion (1990) and Shakoor and Cook (1990). When $b_{v c}=1, p$ approaches zero and $d_{m}$ approaches the geometric mean; when $b_{v c}=0, p$ approaches -1 and $d_{m}$ approaches the harmonic mean. These mean values at high and low $b_{v c}$ are consistent with those suggested by Koltermann and Gorelick (1995) and Kamann et al. (2007). 


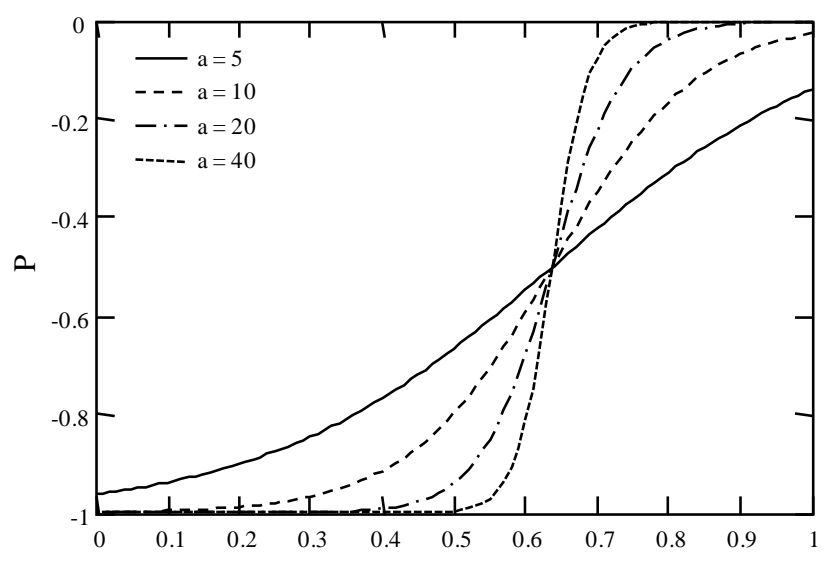

Figure 2.2. Typical Curves of Power $p$ Versus the Coarse Fraction Described by Equation (2.7). The critical fraction of the coarse component $b_{v c 0}=0.6$. 


\subsection{Materials and Methods}

Laboratory experiments were carried out to investigate the impacts of gravel fraction on the porosity and hydraulic conductivity of five binary mixtures, represented by letters A through E in Table 3.1. Glass beads of different sizes (Table 3.2; Potters Industries, Inc., Valley Forge, PA) were used as surrogates of gravels and hence the glass beads may be referred to as gravels as well. Either \#20-30 Accusand from Unimin Corporation' (Le Sueur, MN) or Hanford Warden silt loam (Table 3.2) was used to represent the matrix. The reported particle density was $2.50 \mathrm{~g} / \mathrm{cm}^{-3}$ (Potters Industries, Inc. 2005) for glass beads, $2.664 \mathrm{~g} / \mathrm{cm}^{-3}$ for Accusand (Schroth et al. 1996), and $2.72 \mathrm{~g} / \mathrm{cm}^{-3}$ for the silt loam (Gee et al. 1989).

Table 3.1. Mixtures of Coarse and Fine Components Used

\begin{tabular}{cccc}
\hline Mixtures & Coarse Component & Fine Component & Particle Size Ratio $^{(\mathrm{a})}$ \\
\hline A & $2 \mathrm{~mm}$ Glass Beads & \#20-30 Accusand & 3.5 \\
B & $5 \mathrm{~mm}$ Glass Beads & \#20-30 Accusand & 7.6 \\
C & $14 \mathrm{~mm}$ Glass Beads & \#20-30 Accusand & 10.7 \\
D & $50 \mathrm{~mm}$ Glass Beads & \#20-30 Accusand & 18.0 \\
E & 5 mm Glass Beads & Hanford's Warden & 280.0
\end{tabular}

(a) Ratio of the representative particle diameter of the coarse component to that of the fine component.

Table 3.2. Properties of the Pure-Phase Components

\begin{tabular}{cccc}
\hline Name & $\begin{array}{c}K_{s} \\
\left(\mathrm{~m} \mathrm{~s}^{-1}\right)\end{array}$ & $\begin{array}{c}\text { Effective Diameter } \\
(\mathrm{mm})^{(\mathrm{a})}\end{array}$ & $\begin{array}{c}\text { Porosity } \\
(-)\end{array}$ \\
\hline 2 mm Glass Beads & $1.79 \times 10^{-2}$ & 1.9 & 0.349 \\
5 mm Glass Beads & $1.03 \times 10^{-1}$ & 4.2 & 0.363 \\
14 mm Glass Beads & $2.53 \times 10^{-1}$ & 5.9 & 0.381 \\
50 mm Glass Beads & $1.16 \times 10^{0}$ & 9.9 & 0.429 \\
\#20-30 Accusand & $1.94 \times 10^{-3}$ & 0.55 & 0.362 \\
Hanford's Warden Silt Loam & $2.33 \times 10^{-6}$ & 0.015 & 0.413 \\
\hline
\end{tabular}

(a) The representative particle diameter was determined using the measured saturated hydraulic conductivity and Equation (2.5).

For each mixture, porosity and saturated hydraulic conductivity were measured for 11 different proportions of coarse and fine components from pure coarse to pure fine with a fraction interval (by weight) of about $10 \%$. The porosity of each mixture or a pure phase was determined after measuring its bulk density $\left(\rho_{b m}\right)$ as follows:

$$
\phi_{m}=1-\rho_{b m}\left(\frac{b_{w c}}{\rho_{p c}}+\frac{b_{w f}}{\rho_{p f}}\right)
$$


where $b_{w}$ and $\rho_{p}$ are the component fraction by weight and the particle density, respectively. To estimate the porosity or the hydraulic conductivity of the mixture, the volume fraction is needed. To convert $b_{w}$ to $b_{v}$, it is assumed that the fine component in a mixture has the same bulk density $\left(\rho_{b f}\right)$ as it has in the pure phase. Then, the conversion between the mass and volume fraction can be obtained by $b_{v f}=b_{w f} \rho_{b m} / \rho_{b f}$.

The saturated hydraulic conductivity of each mixture or pure phase was measured using a constant head method in a flow cell. The flow cell had an internal diameter of $0.2 \mathrm{~m}$ and a height of $0.4 \mathrm{~m}$ with a sample height of about $0.3 \mathrm{~m}$ and tubes with internal diameters of $0.025 \mathrm{~m}$ were used for water supply. Two manometers were connected to the water reservoirs below and above the soil sample for the measurement of water heads. For the $K_{s}$ measurement of each sample, four to six heads were applied and corresponding flux rates were measured followed by the examination of the linearity between flux rate and hydraulic heads. Data that showed nonlinear relationships indicated possible flow restriction by system or nonlaminar flow and were discarded. The measured $K_{s}$ values of the pure components for making mixtures are summarized in Table 3.2. The $d_{m}$ of the pure phase were calculated with Equation (2.5) and are also listed in Table 3.2. These $d_{m}$ for the pure phases were used to predict the representative particle diameter of mixtures using Equation (2.6). 


\subsection{Result and Discussions}

In this section, we present the measured and predicted porosity and hydraulic conductivity of the mixtures. The proposed models are then applied to two data sets in the literature.

\subsection{Porosity and the Mixing Coefficient}

The porosities of the mixtures at the different coarse-component fraction $b_{v c}$ are shown by the circles in Figure 4.1. Each curve is composed of one decreasing and one increasing line segment separated by a minimum porosity when the coarse fraction was at approximately $1-\phi_{c}$. This behavior is in agreement with the previous findings although the packings in our experiments were not ideal, as will be shown later by the mixing coefficients. As expected, for all of the mixtures except $\mathrm{D}$, when the two mixing components with distinct particle sizes mixed together, the porosity of the mixture varied between the upper and lower bounds due to nonideal mixing. For mixture D (50-mm glass beads and \#20-30 Accusand), the mixing was ideal or near ideal as suggested by the mixing coefficients; the measured porosity at relatively low $b_{v c}$ was slightly less than the lower bound values due to possible experiment error.

The mixing coefficients of the mixtures were calculated using Equation (2.3) and are shown in Figure 4.2. For mixtures A, B, and C, the $\lambda$ values varied between $19 \%$ and $77 \%$, which indicates nonideal mixing in the range from $b_{v c}=0.1$ to 0.9 . The $\lambda$ values varied between $43 \%$ and $100 \%$ for $\mathrm{D}$ and $\mathrm{E}$. Ideal mixing occurred for $\mathrm{D}$ when $b_{v c}<0.4$ and for $\mathrm{E}$ when $b_{v c}=0.14$. Although the mixing coefficient varies with the packing condition and gravel content, it seems that using a constant $\lambda$ is generally acceptable for calculating the porosities of the mixtures because $\lambda$ has smaller impacts when there is a larger deviation of $b_{v c}$ from $1-\phi_{c}$. Generally, the average mixing coefficients, $\lambda_{\text {avg }}$, increased as the particle size ratio of coarse to fine components increased (Figure 4.3). When the $d_{c} / d_{f}$ ratio is less than about 21, we use a linear regression fit to $\lambda_{\text {avg }}$ versus $\mathrm{d}_{\mathrm{c}} / \mathrm{d}_{\mathrm{f}}$ data set to approximate $\lambda_{\text {avg }}$ :

$$
\lambda_{\text {avg }}=0.0363\left(d_{c} / d_{f}\right)+0.2326, \quad r^{2}=0.9703
$$

The mixing coefficient may be set to unity for large $\mathrm{d}_{\mathrm{c}} / \mathrm{d}_{\mathrm{f}}$ ratios. Comparisons of measured and predicted porosities of five mixtures of coarse and fine components using $\lambda_{\text {avg }}$ are shown in Figure 4.1. The results indicate that the mixing coefficient model using the $\lambda_{\text {avg }}$ can predict the measurement quite well; the ideal-mixing model generally underestimated porosity and may be acceptable when the coarseto-fine ratio is relatively large (e.g., for mixture D); and the zero-mixing significantly overestimated porosity for all the mixtures.

\subsection{Saturated Hydraulic Conductivity of Mixtures}

The measured saturated hydraulic conductivities of mixtures A through $\mathrm{E}$ are shown by the circles in Figure 4.4. For each of the mixtures, as the gravel content increased, $K_{s m}$ decreased slightly to a minimum and then increased sharply. This is because, when the gravel fraction was low, it embedded in the matrix and hence blocked some flow paths and reduced the porosity, as indicated by the ideal packing 
model. Consequently, $K_{s m}$ slightly decreased with increasing gravel content. For the five mixtures, the maximum reduction in $K_{s m}$ was no more than $50 \%$ of the $K_{s}$ of the fine component.
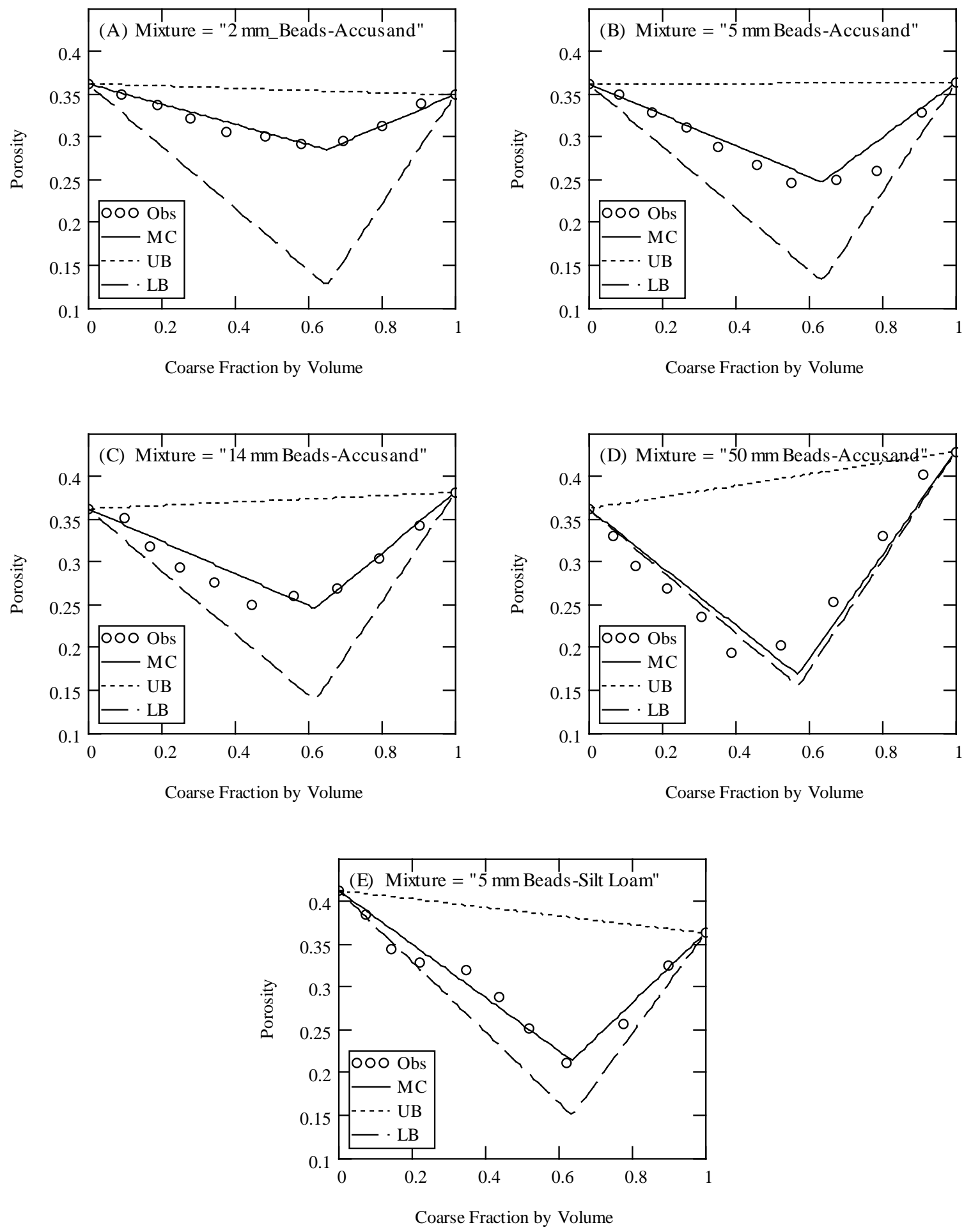

Figure 4.1. Measured (circles) and Predicted (lines) Porosities of Mixtures of Coarse and Fine Components (MC: mixing coefficient model; UB: upper bound of porosity; LB: lower bound of porosity.) 


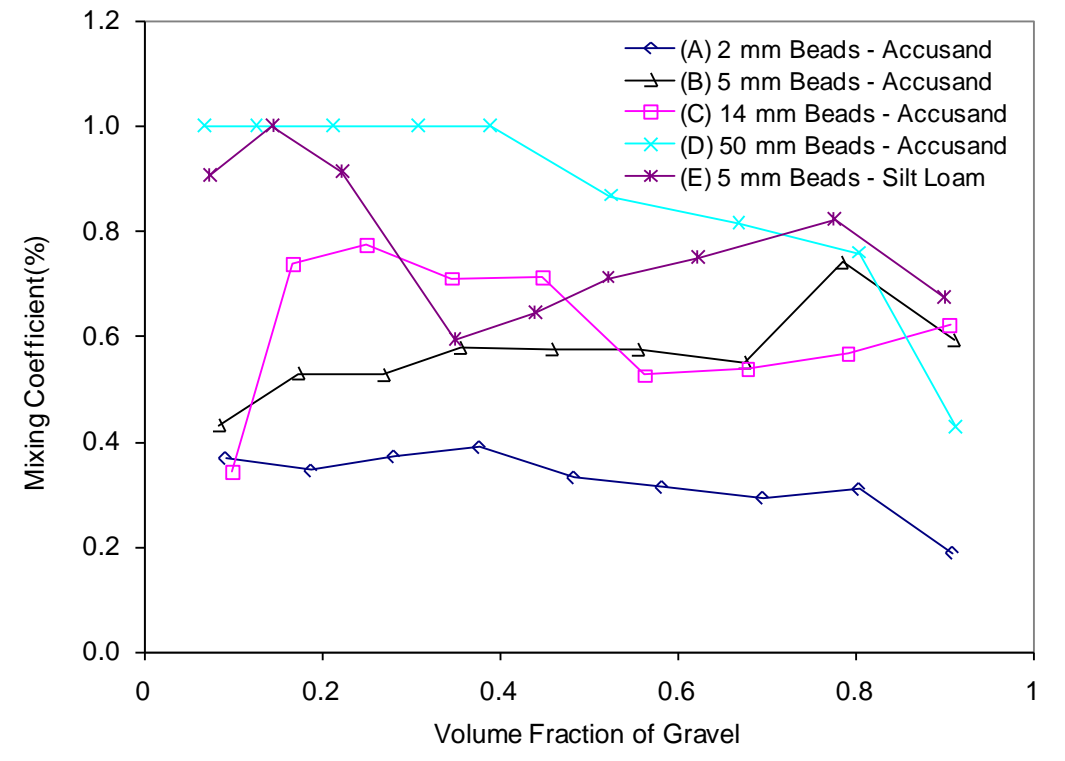

Figure 4.2. Mixing Coefficients of Mixtures of Coarse and Fine Components

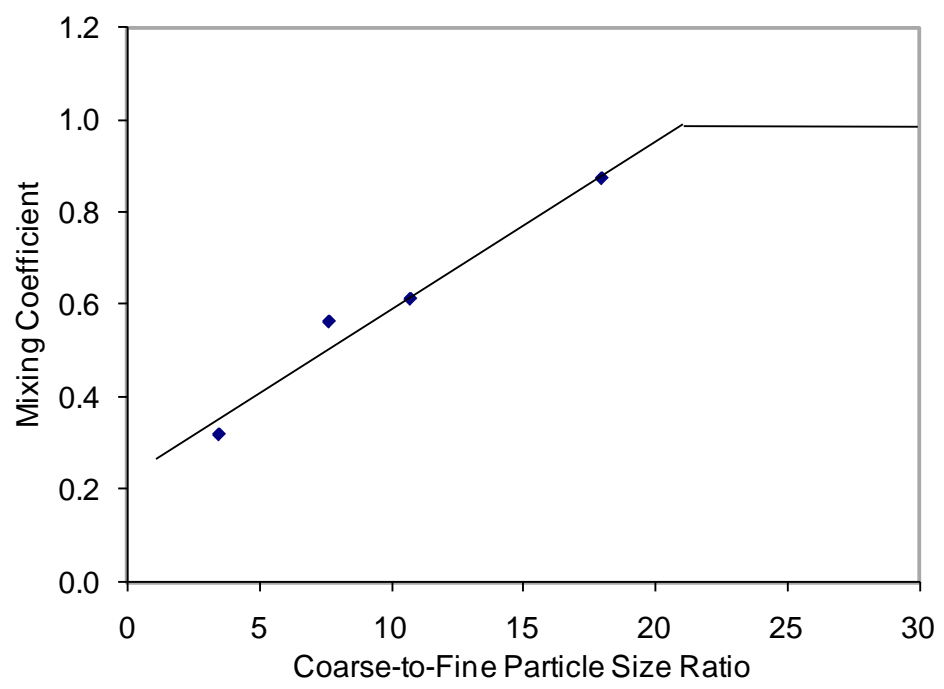

Figure 4.3. The Average Mixing Coefficients of Mixtures of Coarse and Fine Components (Points: measurements; slope line: linear regression; horizontal line: maximum value of the mixing coefficient.)

When the gravel content is relatively high (e.g., $>b_{c v 0}$ ), connected large pores were formed among the gravels and hence $K_{s m}$ increased sharply with the increasing gravel fraction by as large as orders magnitude. Generally, the gravel effects on $K_{s m}$ were larger when the particle size ratio was larger. Although the increasing trends for $\mathrm{C}$ and $\mathrm{D}$ were slightly different from those for $\mathrm{A}, \mathrm{B}$, and $\mathrm{E}$, we attributed these to be artifacts of the experimental method rather than normal behavior. For $C$ and $D$, due to the relatively large particle size ratio and narrow particle size distribution for each of the components, instead of a random distribution, the fine particles tended to fall to the bottom of the coarse structure when the particle size contrasts were relatively large. We observed that mixtures $\mathrm{C}$ and $\mathrm{D}$ at very high 
gravel fractions (about 0.8 and higher) were composed of two distinctly layers: one layer formed with the two components at the lower part of the column and the other formed with the pure coarse component at the upper portion of the column. Consequently, the measured $K_{s m}$ is lower than it should be.
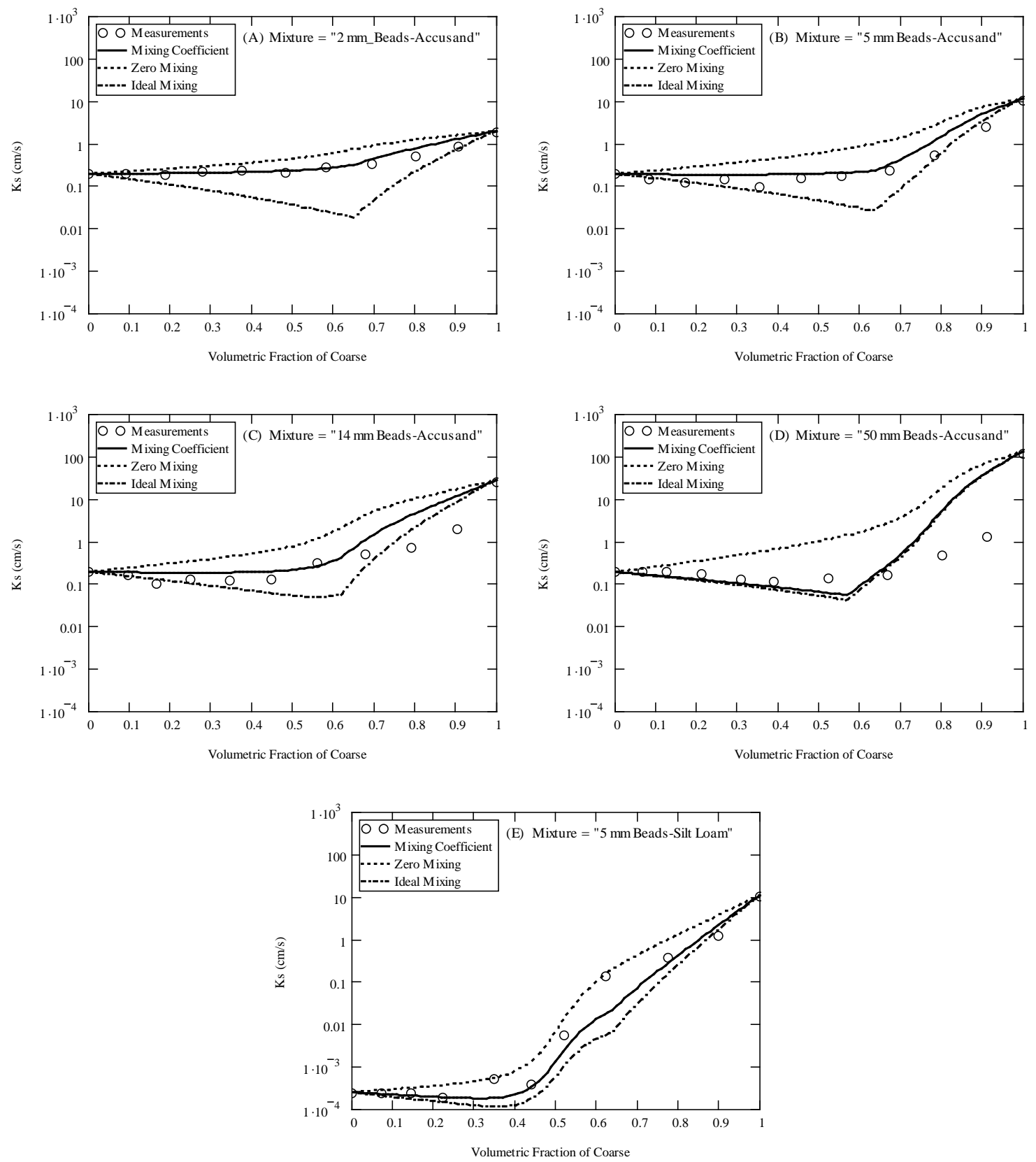

Figure 4.4. Measured (circles) and Predicted (lines) Saturated Hydraulic Conductivities of Binary Mixtures when Zero-Mixing, Ideal-Mixing, and Mixing-Coefficient Porosity Models were Used. Other parameters: $a=20$ for all mixtures; $b_{v c 0}$ values: (A) $1-\phi_{c}$, (B) $1-0.5 \phi_{c}$, (C) $1-\phi_{\mathrm{c}}$, (D) $1-0.5 \phi_{\mathrm{c}}$, and (E) $1-1.5 \phi_{\mathrm{c}}$. 
The critical gravel fraction corresponding to the minimum $K_{s m}$ (Figure 4.4) might be greater or less than 1- $\phi_{c}\left(=0.6\right.$ if $\phi_{c}$ takes a typical value of 0.4$)$, the theoretical value based on the ideal packing model, because for nonideal packing, part of the gravel was mixed with the fine matrix and the nonmixed part stayed together as gravel clusters. The nonmixed portion of gravels tended to increase $K_{s m}$, while the mixed portion tended to reduce the bulk porosity and hence $K_{s m}$. The total effects of the mixed and unmixed gravels determined the critical fractions. The packing procedures might also have significant impacts on the continuity of the macro-pores among the unmixed gravels. Based on our observations, $b_{v c 0}$ varied roughly between 0.4 and 0.8 . This suggests that, depending on the packing condition and the degree of mixing, $K_{s m}$ can vary significantly when the gravel fraction is approximately between 0.4 and 0.8. For natural soil-gravel mixtures, the mixing history can have a significant impact on $K_{s m}$. Consequently, accurate prediction of $K_{s m}$ when the gravel content is in this range can be difficult and may be subject to large uncertainty.

Using the power-averaged $d_{m}$ and three porosity models as inputs to the Kozeny-Carmen equation (Equation [(2.5]), the predictions of $K_{s m}$ are shown in Figure 4.4. The results indicate that the model based on the power-averaged $d_{m}$ could reasonably predict the $K_{s m}$ of the mixtures and captured the sharp increase of $K_{s m}$ when the gravel fraction was higher than the critical values. As expected, the hydraulic conductivity tended to be underestimated when the ideal-mixing porosity model was used and overestimated when the zero-mixing porosity model was used. The predictions from the mixingcoefficient porosity model match the measurements the best. For mixtures C and D, there were relatively large discrepancies between the predictions and measurements when the gravel fraction was between about 0.8 and 0.9 . This might be due to measurement errors when, at high gravel content, the fine component tended to go to the lower section of the packing.

The proposed model was used to predict the hydraulic conductivity for binary mixtures from Marion (1990) and Shakoor and Cook (1990) (Figure 4.5). After determining the effective particle size with the power-averaging method, the Kozeny-Carman model was able to predict $K_{s m}$ over the entire range of the gravel fraction for the Marion (1990) data. The model was also able to predict $K_{s m}$ for the Shakoor and Cook (1990) data; however, the $K_{s m}$ tended to be under-predicted at gravel fractions greater than 0.6. Nonetheless, the general similarity between predicted and measured $K_{s m}$ indicates that the poweraveraging method can be used to predict the effective particle size of gravelly soils.

\subsection{Summary and Conclusions}

Experiments using a five binary mixture of glass beads and Accusand or glass beads and a silt loam soil showed that the porosity of a mixture linearly decreased to a minimum value and then increased with the increase in the gravel fraction. The minimum porosity generally occurred at the gravel fraction of $1-$ $\phi_{c}$. A mixing coefficient model was proposed to estimate the porosity of binary mixtures and an average mixing coefficient may be used to estimate the porosity of a mixture without introducing significant error.

The impact of gravel fraction on the saturated hydraulic conductivity was more significant and more complex than it was on porosity. There was a critical gravel fraction, below which gravels block flow and hence the $K_{s m}$ decreased with the increasing gravel fraction. Once the gravel fraction was greater than the critical value, the $K_{s m}$ increased sharply by as large as orders of magnitude due to the formation of continuous large pores. We proposed a power-averaging method to determine the representative particle 
diameter of a binary mixture. The model was tested using experimental data and data from literature, and it was shown to correctly predict the $K_{s m}$ variation when the gravel fraction varied from zero to one.
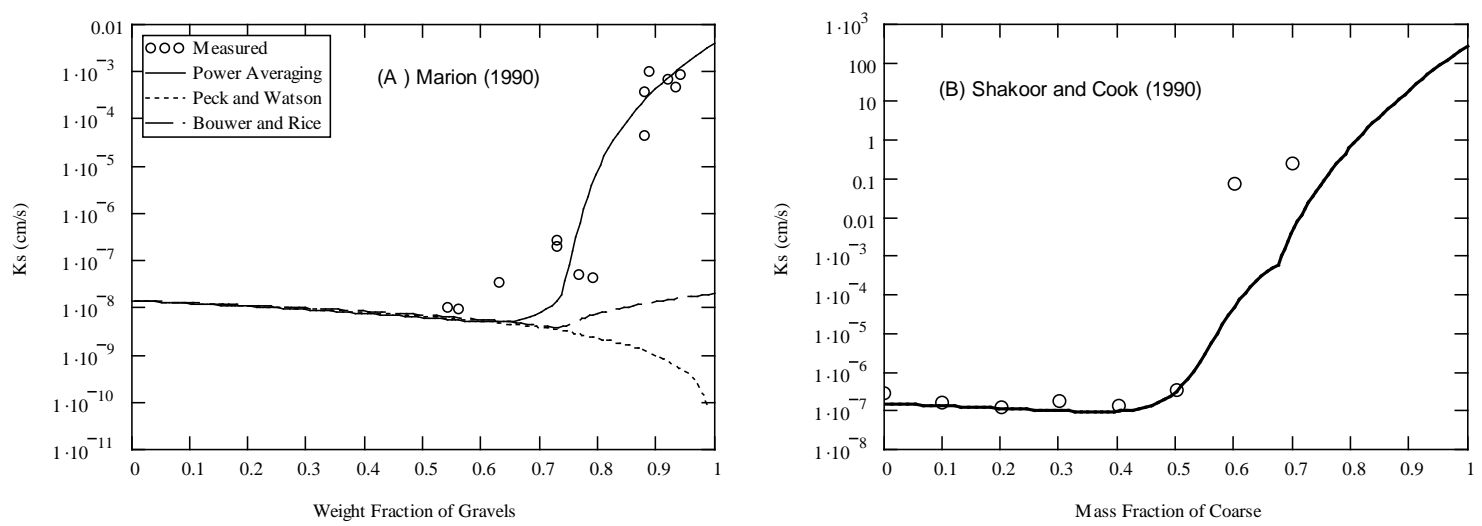

Figure 4.5. Comparison of Predicted Saturated Hydraulic Conductivity and Measured Data from Marion (1990) and Shakoor and Cook (1990). Other model parameters: (A) $d_{c}=0.01 \mathrm{~cm}, d_{f}=$ $0.00003 \mathrm{~cm}, \phi_{\mathrm{c}}=0.32, \phi_{\mathrm{f}}=0.25, \mathrm{a}=20, \mathrm{~b}_{\mathrm{cv} 0}=1-\phi_{\mathrm{c}}, \lambda=1.0 ;$ (B) $\mathrm{d}_{\mathrm{c}}=1.6 \mathrm{~cm}, \mathrm{~d}_{\mathrm{f}}=$ $0.00008 \mathrm{~cm}, \phi_{\mathrm{c}}=0.4, \phi_{\mathrm{f}}=0.28, \mathrm{a}=20, \mathrm{~b}_{\mathrm{cv} 0}=1-1.5 \phi_{\mathrm{c}}, \lambda=1$. 


\subsection{References}

American Society for Testing and Materials (ASTM). 2002. "Standard Practice for Classification of Soils for Engineering Purposes (Unified Soil Classification System).” D2487-00, Annual Book of ASTM Standards, Section Four Construction, 04.08:247-258, Philadelphia, Pennsylvania.

Bear, J. 1972. Dynamics of Fluids in Porous Media. Dover Publications, Inc. New York.

Bouwer, H and RC Rice. 1984. "Hydraulic Properties of Stony Vadose Zones.” Ground Water 22(6):696-705.

Carman, PC. 1937. “Fluid Flow Through Granular Beds. Trans. Inst. Chem. Eng. 15:150.

Clarke, R. 1979. "Reservoir Properties of Conglomerates and Conglomeratic Sandstones.” AAPG Bull. 63:799-809.

Collins, RE. 1961. “Flow of Fluids Through Porous Materials.” Reinhold, New York.

Conca, JL, MJ Apted, W Zhou, RC Arthur, and J Kessler. 1998. "Flow Barrier System for Long-Term High-Level-Waste Isolation: Experimental Results.” Nucl. Technol. 124:88-99.

de Marsily, G. 1986. Quantitative Hydrogeology. 440 pp., Academic, San Diego, California.

Dunn, AJ and GR Mehuys. 1984. "Relationship Between Gravel Content of Soils and Saturated Hydraulic Conductivity in Laboratory Tests.” In JD Nichols (ed.), Erosion and Productivity of Soils Containing Rock Fragments. Special Publication, Vol. 13, Soil Science Society of America, Madison, Wisconsin.

Gee, GW, ML Rockhold, and JL Downs. 1989. Status of FY 1988 Soil-Water Balance Studies on the Hanford Site. PNL-6750, Pacific Northwest Laboratory, Richland, Washington.

Gee, GW and D Or. 2002. “Particle-Size Analysis.” In JH Dane and GC Topp (eds.), Methods of Soil Analysis Part 4 Physical Methods. Pp. 255-293, Soil Science Society of America, Inc. Madison, Wisconsin.

Kamann, PJ, RW Ritzi, DF Dominic, and CM Conrad. 2007. "Porosity and Permeability in Sediment Mixtures”. Ground Water, 45(4):429-438.

Koltermann CE and SM Gorelick. 1995. "Fractional Packing Model for Hydraulic Conductivity Derived from Sediment Mixtures.” Water Resour. Res. 31(12):3283-3297.

Kozeny, J. 1927. “Uber kapillare Leitung des Wassers.” In Boden, Sitzungsber Akad. Wiss. Wien Math. Naturwiss. Kl., Abt. 2a, 136:271-306.

Marion, D. 1990. Acoustical, Mechanical, and Transport Properties of Sediments and Granular Materials. Ph.D. dissertation, 136 pp., Stanford University, Stanford, California. 
Mehuys, GR, LH Stolzy, J Letey, and LV Weeks. 1975. "Effect of Stones on the Hydraulic Conductivity of Relatively Dry Desert Soils.” Soil Sci. Soc. Am. Proc. 39:37-42.

Milczarek, MA, D Zyl, S Peng and RC Rice. 2006. "Saturated and Unsaturated Hydraulic Properties Characterization at Mine Facilities: Are We Doing it Right?” 7th International Conference on Acid Rock Drainage, March 26-30, 2006, St. Louis, Missouri. American Society of Mining and Reclamation (ASMR), Lexington, Kentucky.

Peck, AJ and JD Watson. 1979. “Hydraulic Conductivity and Flow in Non-Uniform Soil.” In Workshop on Soil Physics and Field Heterogeneity. CSIRO Division of Environmental Mechanics, Canberra, Australia, February 12-14, 1979.

Potters Industries, Inc. 2007. A-Series Technical Quality Products. Available at http://www.pottersbeads.com/literature/Tech_quality_specifications.pdf.

Ross, B. 1990. “The Diversion Capacity of Capillary Barriers.” Water Resour. Res. 26:2625-2629.

Schroth, MH, SJ Ahearn, JS Selker, and JD Istok. 1996. "Characterization of Miller-Similar Silica Sands for Laboratory Hydrologic Studies.” Soil Sci. Soc. Am. J. 60:1331-1339.

Selker, J. 1997. “Design of Interface Shape for Protective Capillary Barriers.” Water Resour. Res. 33:259-260.

Shakoor, A and BD Cook. 1990. "The Effect of Stone Content, Size, and Shape on Engineering Properties of a Compacted Silty Clay.” Bull. Assoc. Eng. Geol. XXVII(2):245-253.

Shelly, TL, and DE Daniel. 1993. "Effect of Gravel on Hydraulic Conductivity of Compacted Soil Liners.” Journal of Geotechnical Engineering. 119(1):54-68.

Soil Survey Staff. 1975. "Soil Taxonomy: A Basic System of Soil Classification for Making and Interpreting Soil Surveys.” USDA-SCS Agric. Handbook 436, U.S. Government Printing Office, Washington, D.C.

Valentin C. 1994. "Surface Sealing as Affected by Various Rock Fragments Covers in West Africa." Catena 23:87-97.

Yu, AB, J Bridgwater, and A Burgidge. 1997. "On the Modeling of the Packing of Fine Particles.” Powder Technology 92:185-194. 


\section{Distribution}

No. of

Copies

\section{Onsite}

5 Pacific Northwest National Laboratory ZF Zhang

AL Ward

GV Last

MJ Fayer

MD Freshley
No. of

Copies

GeoSystems Analysis, Inc.

JM Keller

PDF

2 CH2M HILL Plateau Remediation Company

BA Williams PDF

R Khaleel

PDF 


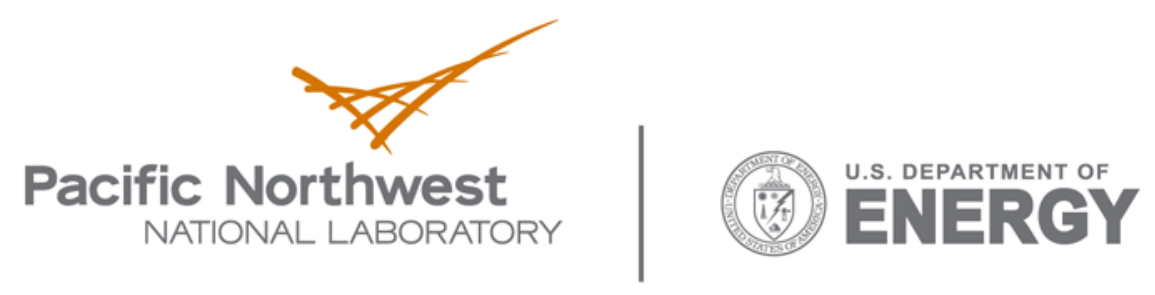

902 Battelle Boulevard

P.O. Box 999

Richland, WA 99352

1-888-375-PNNL (7665)

www.pnl.gov 